\title{
BIOLOGICAL NITROGEN TRANSFORMATION IN AGROCENOSES OF POTATO AND PRODUCTIVITY OF CULTURE IN ORGANIC AGRICULTURE
}

\author{
V. V. Volkohon, S. B. Dimova, K. I. Volkohon, V. P. Horban, M. A. Zhurba, N. P. Shtanko, \\ N. V. Lutsenko, T. Yu. Britan
}

Institute of Agricultural Microbiology and Agroindustrial Manufacture, NAAS, City of Chernihiv

The effect of organic fertilizers (cattle manure and lupine green manure), as well as microbial preparation Biohran on the dynamics of the activity process of nitrogen fixation and $\mathrm{N}_{2} \mathrm{O}$ emissions in the rhizosphere soil of potato plants, crop yield, and product quality have been investigated. The use of manures stimulates activity of nitrogen fixation, but at the same time, accompanied by a significant loss of gaseous nitrogen compounds. The efficiency of Biohran by this agrobackground is largely levelled. Lupine green manure stimulates nitrogenase activity, especially in combination with biopreparation. At the same time, there is a tendency to reduce nitrous oxide emission. Organic fertilizers contributed to a reliable raise of potato yield. Biohran provide productivity gains only on the background of green manure. Microbial preparation contributed to the improvement of quality of production parameters by all studied agrobackgrounds.

Key words: organic agriculture, manure, green manures, microbial preparations, potato.

Currently, many countries actively transit to ecologically-oriented agriculture, including organic. At the same time, limited possibilities of intensification of the nutrition of crops due to high legislative requirements to hygienic cleanliness of products are stimulating. Among compounds of the main elements of plant nutrition under organic agricultural production there is a particular concern about nitrogen, since the use of nitrogen fertilizers is prohibited in this case. In this regard, optimization of process of biological nitrogen transformation in agrocenoses intended to increase supply of "biological" nitrogen to the plants and soils, as well as reduce losses of its gaseous compounds.

The aim of this paper is research of orientation of the process of nitrogen biological transformation under "organic" cultivation of potatoes and impact of the factors of their optimization on the productivity of culture.
Materials and methods. The study was conducted in 2012-2015 under conditions of stationary field experiment of the Institute of Agricultural Microbiology and Agroindustrial Manufacture of the NAAS on leached black soil (pHsal. - 5.30; humus content - 3.03; easily-hydrolysed nitrogen - $95.2 \mathrm{mg} / \mathrm{kg}$; phosphorus $226 \mathrm{mg} / \mathrm{kg}$; exchangeable potassium $108 \mathrm{mg} / \mathrm{kg}$ of soil). In the experiment, potatoes of variety Bellaroza were cultivated. The fowling variants of fertilization were used: without fertilizer; application of $40 \mathrm{t} / \mathrm{ha}$ of litter cattle manure; intermediate green manure - blue lupine.

Manure and mass of green manure were obtained from the soil since autumn.

In addition to organic fertilizers, the scheme of the experiment included the use of Biohran (TU U 24.1-00497360-006: 2009), biological preparation of multifunctional type of action in which the bacterial components (Azospirillum 
brasilense 410) are immobilized in vermicompost (product of manure worm composting). The preparation stimulates plant growth and development, promotes the activity of nitrogen fixation in the root zone, improves phosphorus nutrition of plants.

Placing of plots in the experiment is randomised. The area of one plot is $86 \mathrm{~m}^{2}$. Repeatability - fourfold.

Potential activity of nitrogen fixation and potential emission of $\mathrm{N}_{2} \mathrm{O}$ in the rhizospheric soil of plants was studied in the experiment over time, recording of harvest was performed, qualitative parameters of the products were investigated.

The potential nitrogen fixation activity was measured by acetylene method by addition of glucose solution to the sample weight (5 g) [1]. Gas samples were analyzed on a gas chromatograph "Chrom-4" with a flame ionization detector. Steel sorption column were filled with sorbent Paropak Q 60-80 mesh. Incubator temperature is $40^{\circ} \mathrm{C}$. Gas flow rate: hydrogen - $15 \mathrm{~cm}^{3} / \mathrm{min}$, nitrogen $-100 \mathrm{~cm}^{3} / \mathrm{min}$, air $-500 \mathrm{~cm}^{3} / \mathrm{min}$.

Potential denitrification activity in the rhizospheric soil of potato plants was measured by acetylene method by addition of glucose solution and potassium nitrate to the sample weight (5 g) [2]. Samples were analyzed on a gas chromatograph "Tsvet M500" with a thermal conductivity detector (bridge current of $200 \mathrm{~mA}$ ) on the column with sorbent Paropak Q 60-80 mesh. Column temperature $-25^{\circ} \mathrm{C}$, detector $40^{\circ} \mathrm{C}$, gas flow rate (helium) $-20 \mathrm{~mL} / \mathrm{min}$.

Registration of harvest was performed manually plot-by-plot.

During the study of quality of the products obtained in the experiment, content of nitrates in the tubers was measured potentiometrically [3], the starch content by Ewerse method [4], the content of ascorbic acid - by the method based on reducing properties of vitamin $\mathrm{C}$ [5].

Statistical processing of experimental data was performed by Dospiekhov [6]. For the analysis of variance, computer program Microsoft Office Excel 2003-2007 was utilised.
Thus, the results obtained indicate the need to conduct preliminary manure preparation for application. The use of both studied types of organic fertilizers contributes to a significant growth of potato yield. The use of Biohran in the technologies of potato cultivation helps in improvement of the qualitative parameters of products. Microbial drug, applied by a background of cattle manure application does not provide increase in productivity of culture. The combination Biohran and green manure helps to optimize processes of biological nitrogen transformation in the root zone of plants, provides increase in productivity of potato and improvement of products quality that is extremely important for organic agricultural manufacture. 